\title{
Reduction in surgical wound infection rates associated with reporting data to surgeons
}

\author{
GD TAYLOR MD FRCPC, M BUCHANAN-CHELL RN BSCN, T KIRKLAND RN BSCN, M MCKENZIE RN BSCN CIC, \\ B SUTHERLAND RN BSCN, R WIENS RN BSCN
}

\begin{abstract}
GD Taylor, M Buchanan-Chell, T Kirkland, M McKenzie, B Sutherland, R Wiens. Reduction in surgical wound infection rates associated with reporting data to surgeons. Can $J$ Infect Dis 1994;5(6):263267. Several studies have shown that wound infection (surgical site infection [ssi]) rates fall when surgeons are provided with data on their performance. Since 1987, the authors have been performing concurrent surveillance of surgical patients and confidentially reporting surgeon-specific ssi rates to individual surgeons and their clinical directors, and providing surgeons with the mean rates of their peers. The program has been gradually refined and expanded. Data are now collected on wound infection risk and report risk adjusted rates compared with the mean for hospitals in the United States National Nosocomial Infections Surveillance (NNIS) data bank. Since inception through to December 1993, ssi rates have fallen $68 \%$ in clean contaminated general surgery cases (relative risk [RR] $0.36,95 \% \mathrm{CI} 0.2$ to $0.6, \mathrm{P}=0.0001$ ), $64 \%$ in clean plastic surgery cases (RR $0.35,95 \%$ CI 0.06 to 1.8), $72 \%$ in caesarean section cases (RR $0.23,95 \%$ $\mathrm{CI} 0.03$ to 1.96 ) and $42 \%$ in clean cardiovascular surgery cases (RR $0.59,95 \%$ CI 0.34 to 1.0 ). In clean orthopedic surgery the ssi rate remained stable from 1987 through 1992. In 1993 a marked increase was experienced. Reasons for this are being explored. Overall there was a 32\% decrease in ssi rate between the index year and 1993 or, in percentage terms, $2.8 \%$ to $1.9 \%$ (RR $0.65,95 \%$ CI 0.51 to $0.86, \mathrm{P}=0.002$ ). SSI surveillance should become standard in Canadian hospitals interested in improving the quality of surgical care and reducing the clinical impact and cost associated with nosocomial infection.
\end{abstract}

Key Words: Data reporting, Surgical site infection. Surgical wound infection rates

\section{Réduction des taux d'infection de plaies chirurgicales associée à la transmission des données aux chirurgiens}

RÉSUMÉ : Diverses études ont révélé que les taux d'infection des plaies opératoires chutent lorsque les chirurgiens sont mis au courant des données sur leur performance. Depuis 1987, les auteurs ont procédé à une surveillance des patients de chirurgie et ont transmis de façon confidentielle les taux d'infection des plaies opératoires aux chirurgiens concernés, ainsi qu'à leur directeur clinique, et ont divulgué à ces mêmes chirurgiens le taux moyen obtenu par leurs collègues. Le programme s'est graduellement raffiné et élargi. Les données sont désormais recueillies sur les risques d'infection des plaies opératoires et font état de taux de risque ajustés, avec une moyenne, pour les hôpitaux inscrits à la United States National Nosocomial Infections Surveillance data bank. Depuis sa création en décembre 1993, les taux d'infection ont chuté de $68 \%$ dans les cas de chirurgie générale contaminée propre (risque relatif [RR] 0,36, $95 \%$ IC 0,2 à 0,6.

voir page suivante

Department of Medicine, University of Alberta and Infection Control Unit, University of Alberta Hospitals, Edmonton, Alberta Correspondence and reprints: Dr GD Taylor, 2E4.11 WMC, University of Alberta Hospitals, 8440-112 Street, Edmonton, Alberta T6G 2B7. Telephone (403) 492-7137, Fax (403) 492-7786

Received for publication March 25, 1994. Accepted June 30, 1994 


\begin{abstract}
$\mathrm{P}=0.0001$ ), de $64 \%$ dans les cas de chirurgie esthétique propre (RR 0,35, $95 \%$ IC 0,06 à 1,8), de $72 \%$ dans les cas de césariennes (RR 0,23, $95 \%$ IC 0,3 à 1,96), et de $42 \%$ dans les cas de chirurgie cardiovasculaire propre (RR 0.59, $95 \%$ IC 0,34 à 1.0) dans la chirurgie orthopédique propre, le taux d'infection de la plaie opératoire est demeuré stable de 1987 à 1993. En 1993, une augmentation marquée a été observée. Les raisons de cet état de fait sont à l'étude. Globalement, une augmentation du taux d'infection des plaies opératoires de $32 \%$ a été observée entre l'année index et 1993, ou en termes de pourcentage, de $2,8 \%$ à $1.9 \%$ (RR 0,65, $95 \%$ IC 0,51 à 0,86, $\mathrm{P}=0,002$ ). La surveillance épidémiologique des infections des plaies opératoires devrait devenir une norme dans les hôpitaux canadiens qui sont intéressés à améliorer la qualité des soins chirurgicaux et à réduire l'impact clinique et les coûts associés à l'infection nosocomiale.
\end{abstract}

$\mathrm{N}$ OSOCOMIAL INFECTIONS OCCUR IN ABOUT 6\% OF PATIENTS admitted to acute care hospitals and have been identified as a serious public health risk and drain of resources from the health care system (1-3). Surgical wound infection, also called surgical site infection (ssi), is a major subgroup of all nosocomial infections. Surveillance for ssi and reporting their occurrence to surgeons can reduce their frequency. In 1915 Brewer (4) reported a reduction in the rate of wound infections in clean surgeries from $39 \%$ to under $1 \%$ following institution of a program of reporting infection rates to surgeons. Subsequently, Cruse and Foord (5) and others $(1,6-8)$ confirmed the effectiveness of ssi surveillance programs. Despite this, in a survey we carried out of Canadian acute care hospitals in 1989 (9), only 38\% reported that they conducted ssi surveillance. No Canadian data have been recently published on the effect of ssi surveillance on infection rates. We therefore carried out this review of our experience.

\section{PATIENTS AND METHODS}

The University of Alberta Hospital is an acute tertiary care hospital and the major teaching centre of the University of Alberta, Faculty of Medicine. All forms of surgical care, including pediatric surgery, obstetric/ gynecology and multiorgan transplantation are provided. Substantial reduction in bed numbers has occurred since 1992, reducing the hospital's capacity from 1100 in 1991 to 850 in 1993. Beginning in 1987, annual data concerning wound infections occurring in surgical patients at our institution have been collected. Originally, all in-patient procedures in general surgery, cardiothoracic surgery, neurosurgery and orthopedic surgery were surveyed. Patients undergoing in-patient surgical procedures are followed by infection control practitioners from two days postsurgery for a 14-day period or until discharge, whichever comes first. Occasional postdischarge telephone surveys have been carried out to detect infections occurring postdischarge (10) but these are not routinely sought. Patient incisions are directly inspected by the infection control practitioner. Nonincisional wound infections are detected by chart review. A standardized definition of wound infection is employed, which was slightly modified in 1992 to reclassify infections $(11,12)$. The 1992 definition subcategorizes SsI into superficial incisional, deep incisional and organ/space ssi. A superficial inci- sional infection is associated with pain, swelling, redness or heat, or is deliberately opened by the surgeon for drainage of pus or isolation of an organism from an aseptically obtained culture (excluding stitch abscess). A deep incisional ssi involves deep soft tissue (eg, muscle or fascia). An organ/space infection involves sites open or manipulated during the procedure, other than the incision.

Over the seven study years, modifications of the protocol occurred in response to requests from surgical groups and to improve the efficiency and widen the scope of the program. Contaminated and dirty surgical procedures are no longer followed. In 1991 plastic surgery patients began to be surveyed and in 1992 caesarean section patients were added. From 1986 to 1992, surveillance was carried out for all patients undergoing specified procedures. Beginning in 1992, absences of an infection control practitioner, for vacation or other reasons, were no longer covered by another practitioner. As a result, both numerators (infected cases) and denominators (procedures) were no longer complete and the program became, in effect, a convenience sample survey. To permit comparison of the results of the present study with those of patients in the United States National Nosocomial Infections Surveillance (NNIS) data bank (13), beginning in 1992 data were collected on patient wound infection risk for all patients in the surveillance program and risk adjusted wound infection rates by comparison with NNIS were reported. Elements of this risk data include: wound classification on the clean - dirty spectrum; American Society of Anaesthesiology risk score (14); and procedure duration. These data allow patient groups undergoing the same procedure to be subcategorized into four wound infection risk strata, and for risk adjusted comparison of data with rates from NNIS.

Surgical infection reports were initially issued monthly, but since 1993 have been issued quarterly to allow for greater statistical power, with annual summaries. Individual surgeons are given their results, with information on identified infected patients and mean rates for their peers stratified by surgical class. Clinical surgical directors and clinical departmental chairpersons are provided with each individual surgeon's rates as well as divisional data. Surgeon-specific infection rates are considered confidential, and are not shared with administrators, other physicians or any other 
TABLE 1

Trends in wound infection rates by division and wound class

\begin{tabular}{|c|c|c|c|c|c|}
\hline Service & Surgical class & Index year & Index infection rate (\%) & 1993 infection rate $(\%)$ & Rate difference $(\%)$ \\
\hline General surgery & $\begin{array}{l}\text { Clean } \\
\text { Clean-contaminated }\end{array}$ & 1987 & $\begin{array}{l}16 / 938(1.7) \\
74 / 1291(5.7)\end{array}$ & $\begin{array}{r}7 / 407(1.7) \\
14 / 684(2.1)\end{array}$ & $\begin{array}{c}0 \\
-3.6\end{array}$ \\
\hline Cardiovascular surgery & $\begin{array}{l}\text { Clean } \\
\text { Clean-contaminated }\end{array}$ & 1987 & $\begin{array}{c}36 / 1010(3.6) \\
3 / 90(3.3)\end{array}$ & $\begin{array}{r}20 / 958(2.1) \\
3 / 134(2.2)\end{array}$ & $\begin{array}{l}-1.5 \\
-1.1\end{array}$ \\
\hline Neurosurgery & $\begin{array}{l}\text { Clean } \\
\text { Clean-contaminated }\end{array}$ & 1987 & $\begin{array}{l}9 / 563(1.6) \\
1 / 62(1.6)\end{array}$ & $\begin{array}{l}10 / 415(2.4) \\
2 / 20(10)\end{array}$ & $\begin{array}{l}+0.8 \\
+8.6\end{array}$ \\
\hline Orthopedic surgery & $\begin{array}{l}\text { Clean } \\
\text { Clean-contaminated }\end{array}$ & 1987 & $\begin{array}{l}2 / 612(0.3) \\
0 / 36(0)\end{array}$ & $\begin{array}{l}21 / 930(2.3) \\
0 / 12(0)\end{array}$ & $\begin{array}{c}+2.0 \\
0\end{array}$ \\
\hline Plastic surgery & $\begin{array}{l}\text { Clean } \\
\text { Clean-contaminated }\end{array}$ & 1991 & $\begin{array}{l}5 / 255(2.0) \\
1 / 46(2.2)\end{array}$ & $\begin{array}{l}2 / 290(0.7) \\
0 / 16(0)\end{array}$ & $\begin{array}{l}-1.3 \\
-2.2\end{array}$ \\
\hline Caesarean section & & 1992 & $5 / 457(1.1)$ & $1 / 407(0.3)$ & -0.8 \\
\hline All areas & & & $152 / 5360(2.8)$ & $80 / 4273(1.9)$ & -0.9 \\
\hline
\end{tabular}

group or individual. Reports containing surgeon-specific data refer to physicians in a coded fashion to enhance confidentiality. Annual reports include trends over time, procedure-specific infection rates and (since 1992) risk adjusted comparisons of procedure-specific rates with the mean rates of patients in the NNIS system. Statistical analyses of infection rates were performed using Mantel-Haenszel $\chi^{2}$, Yates corrected, as calculated by the statistical program of EPI Info, version 5.0 software program (USD Inc, Georgia).

\section{RESULTS}

Table 1 shows trends in SsI rates by service and surgical wound class from the index year, the first year of surveillance, through 1993. These data do not include information from postdischarge surveys carried out by the authors, and they compare the index year with 1993 only for those procedures followed throughout the study period. With the exception of neurosurgery and orthopedic surgery there was a consistent pattern of reduction in infection rates. The most spectacular improvement occurred in general surgery clean contaminated cases (Figure 1) where the infection rate progressively fell from 5.7 in 1987 to 2.1 in 1993 (relative risk [RR] $0.36,95 \%$ cI 0.20 to $0.63, \mathrm{P}=0.0003$ ). In neurosurgery, infection rates remained largely stable, with 1993 rates being slightly higher than 1987 (RR 1.5, CI 0.6 to $3.7, \mathrm{P}=0.5$ ). In orthopedic surgery, between 1987 and 1992 infection rates remained stable. In 1993 there was a marked increase in the clean SSI rate (RR compared with 1992 was $4.5,95 \%$ CI 1.6 to 11.8 , $\mathrm{P}=0.002$ ). The 1993 experience in orthopedic surgery is being examined in more detail. Preliminary analysis reveals widespread increases in infection rates not confined to any one procedure or surgeon. No common microorganism was identified in infected cases. Males had a higher infection rate than females $13.6 \%$ compared with $1.3 \%, \mathrm{P}=0.02$ ). This sex difference persisted when data were stratified by NNIS risk group and was most pronounced in the lowest risk stratum (male infection rate $=3.4 \%$, female rate $=0.8 \%$ ). Data from

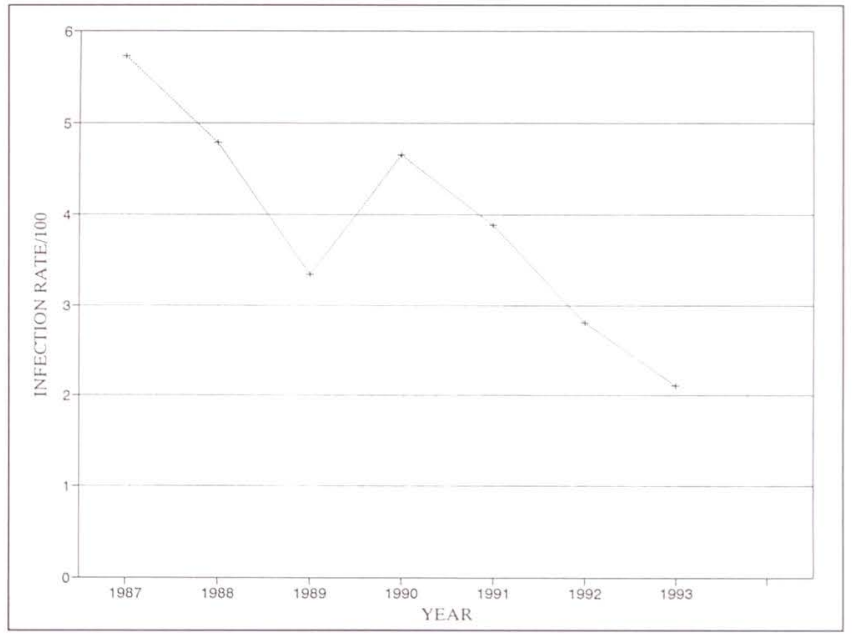

Figure 1) Clean contaminated wound infection rate for general surgery

the first quarter of 1994 showed a reduction in orthopedic infection rates to their previous baseline.

For all surveyed areas, the SSI rate for procedures still being followed in 1993 fell from 2.8\% to $1.9 \%$ between the index year, ie, the first year surveyed in that division, and 1993 (RR 0.65, 95\% CI 0.51 to 0.86 . $\mathrm{P}=0.002$ ). Excluding the unique orthopedic experience slightly reduces the overall relative risk estimate to 0.61 (95\% CI 0.46 to 0.83 ).

\section{DISCUSSION}

Before and after studies, such as the one reported here, while very common in public health and hospital infection control programs, are prone to many biases and confounding factors, which make their interpretation difficult. Changes occurred in the survey population between the index year and 1993. Patients are now discharged earlier from hospital, reducing their opportunity to have a wound infection diagnosed. The acuity of our in-patient surgical population is rising. For example, in 1987 the general surgery database included 492 cholecystectomies with an infection rate of only 
$2.2 \%$ compared with $5.7 \%$ for all clean contaminated cases. By 1993 there were only 107 of these low risk patients in the database. New high risk procedures such as heart-lung and liver transplantation were added between the index year and 1993. The relative weight of these countervailing trends cannot be assessed completely. Similarly, co-interventions between the index year and 1993 could confound our results. We frequently discuss ssi results with our surgical colleagues and are unaware of any important intervention, such as changes in antimicrobial prophylaxis, made during the study period. Because of these biases and the potential for confounders, our estimate of the reduction in wound infection rate is not precise. However, the relative risk of wound infection in 1993 was only 0.65 for all surveyed areas compared with the index year; this effect size is comparable with the effect of surveillance on wound infection rates in other published studies for previous years in other countries (5-8). The consistency of our results with other reports supports the value of SSI surveillance as an effective approach to the reduction of their frequency. Of the six surgical areas surveyed, four (general surgery, cardiovascular surgery, plastic surgery and caesarian section cases in obstetric/gynecology) experienced a reduction in SsI rate associated with reporting of data. In neurosurgery, rates fluctuated, and in 1993 were slightly higher than the index year, though this increase was not statistically significant and was associated with wide confidence intervals. In orthopedic surgery, following six years of relatively stable rates, a marked increase occurred in 1993. Reasons for this increase

\section{REFERENCES}

1. Haley RW, Culver DH, White JW, et al. The efficacy of infection surveillance and control programs in preventing nosocomial infections in US hospitals. Am J Epidemiol 1985; 121:182-205

2. Public health focus: surveillance, prevention, and control of nosocomial infections. MMWR 1992;41:783-7.

3. Penin GB, Ehrenkranz NJ. Priorities for surveillance and cost-effective control of postoperative infection. Arch Surg 1988: 123: 1305-8.

4. Brewer GE. Studies in aseptic technic with a report of some recent observations at the Roosevelt Hospital. JAMA 1915:64:1369-73.

5. Cruse PJE, Foord R. The epidemiology of wound infection - a 10 year prospective study of 52,939 wounds. Surg Clin North Am 1980;60:27-39.

6. Mead PB, Pories SE, Hall P, Vacek PM, Davis JH, Gamelli RL. Decreasing the incidence of surgical wound infection. Arch Surg 1986;121:458-61

7. Condon RE, Schulte WJ, Malangoni MA, Anderson Teschendorg MJ. Effectiveness of a surgical wound surveillance program. Arch Surg 1983;1 18:303-7.

8. Olson MM, Lee JT. Continuous, 10-year wound infection surveillance. Arch Surg 1990; 125:794-803.

9. Wiens R, Taylor GD. Surgical wound surveillance: current Canadian practices and attitudes of surgeons in one institution. Infect Control Canada 1989;4:9-12.

10. Pearce P, McKenzie M, Taylor G. Wound infections in are not clear but our investigation suggests that this is a true increase (ie, not a result of increased patient acuity) and not a result of the effect of one individual surgeon or common source. The sex difference occurring throughout risk strata suggested that some change in the way males were managed might be responsible. No such change could be identified, and in 1994 rates returned to their previous baseline.

The reductions in ssi rates that have occurred in our hospital should be associated with substantial cost saving. ssi are known to prolong hospital stays markedly (15-18). In a recent study of our own patient population, ssi was associated on average with a prolongation of stay of 19.5 days compared with controls (19). Costs of hospital care are not routinely collected in our hospital; however, we charge other Canadian provincial medical care programs \$1,225/day for a standard hospital bed. ssi surveillance requires about a quarter to a third of the infection control program or, in dollar terms, $\$ 50,000$ to $\$ 100,000 /$ year. Thus, even minor reductions in SSI rates are likely to be highly cost-effective because the increased cost of treating the ssi that likely would have occurred without surveillance would far exceed this figure.

SSI surveillance has been widely recommended (2022) as a highly effective hospital infection control practice. Our experience supports these recommendations. It is hoped that with increased awareness of the benefits to be obtained, more Canadian hospitals, if they have not already done so, will adopt the practice, thereby preventing more of these surgical complications.

orthopedic surgery: effect of extended surveillance on infection rate. Can J Surg 1991;34:31-4.

11. Garner JS, Jarvis WR, Emor TG, Horan TC, Hughes JM. CDC definitions for nosocomial infections, 1988. Am J Infect Control 1988; 16:128-40.

12. Horan TC, Gaynes RP, Martone WJ, Jarvis WR, Emor TG. CDC definitions of nosocomial surgical site infections, 1992: a modification of CDC definitions of surgical wound infections. Am J Infect Control 1992:20:271-4.

13. Marton WJ, Gaynes RP, Horan TC, et al. Nosocomial infection rates for interhospital comparison: limitations and possible solutions. A report from the National Nosocomial Infections Surveillance (NNIS) System. Infect Control Hosp Epidemiol 1991;12:609-21.

14. Owens WD, Felts JA, Spitznagel EL. ASA physical status classifications: a study of consistency of ratings. Anesthesiology 1978;49:239-42.

15. Haley RW, Schaberg DR, Crossley KB, Von Allmen SD, McGowan JE Jr. Extra charges and prolongation of stay attributable to nosocomial infections: a prospective interhospital comparison. Am J Med 1981;70:51-8.

16. Stone HH, Haney BB, Kolb LD, Geheber CE, Hooper CA. Prophylactic and preventive antibiotic therapy: timing, duration and economics. Ann Surg 1979;189:691.

17. Rubinstein E, Green M, Modan M, Amit O, Bernstein L, Rubinstein A. The effects of nosocomial infections on the length and costs of hospital stay. Antimicrob Agents 
Chemother 1982;9(Suppl A):93-100.

18. Green MS, Rubinstein E, Amit P. Estimating the effects of nosocomial infections on the length of hospitalization.

$\mathrm{J}$ Infect Dis 1982:145:667-72.

19. Taylor GD, Kirkland T, McKenzie M, Sutherland B. Wiens R. Effect of surgical wound infection on length of stay in a Canadian hospital. Fourth Annual Meeting of The Society for Hospital Epidemiology of America, New Orleans,
March 20-22, 1994. (Abst)

20. Condon RE, Haley RW, Lee JT, Meakings JL. Does infection control control infection? Arch Surg 1988; 128:250-6.

21. Nichols RL. Surveillance of the surgical wound. Infect Control Hosp Epidemiol 1990: 1 1:513-4.

22. Lee JT. Wound infection surveillance. Infect Dis Clin North Am 1992:6:643-55. 


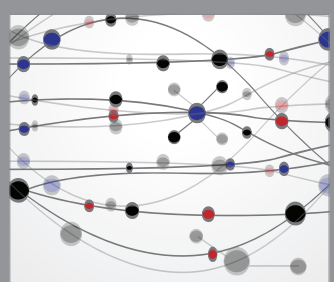

The Scientific World Journal
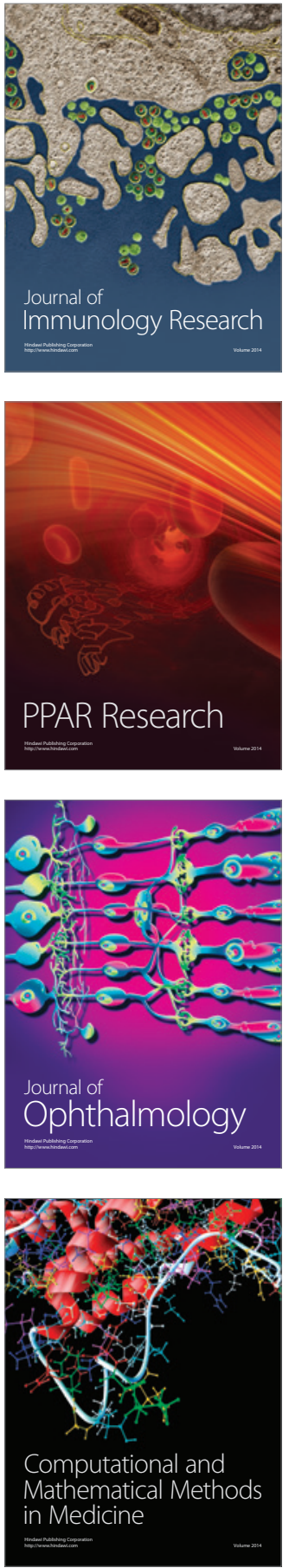

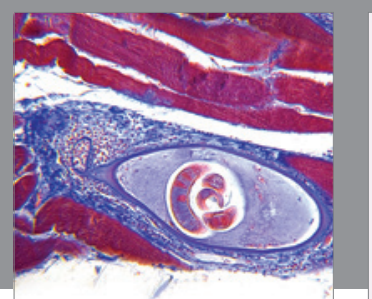

Gastroenterology Research and Practice

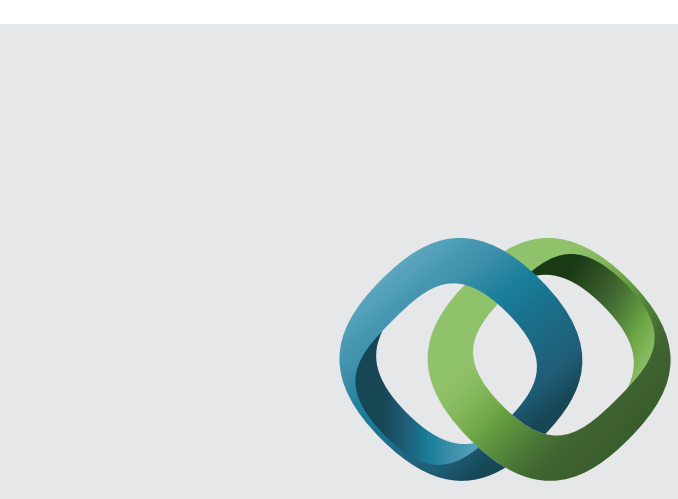

\section{Hindawi}

Submit your manuscripts at

http://www.hindawi.com
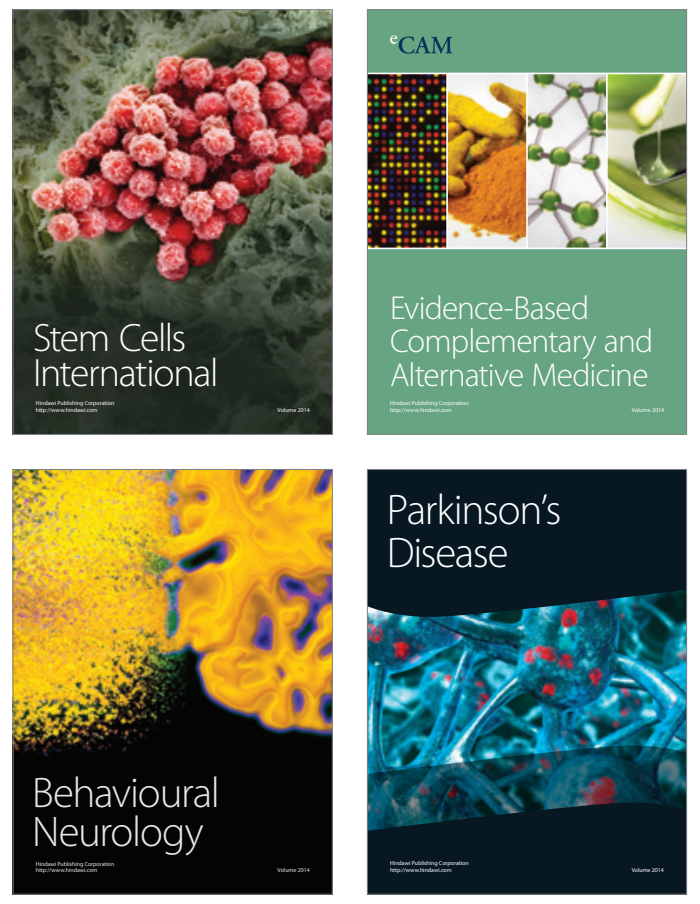
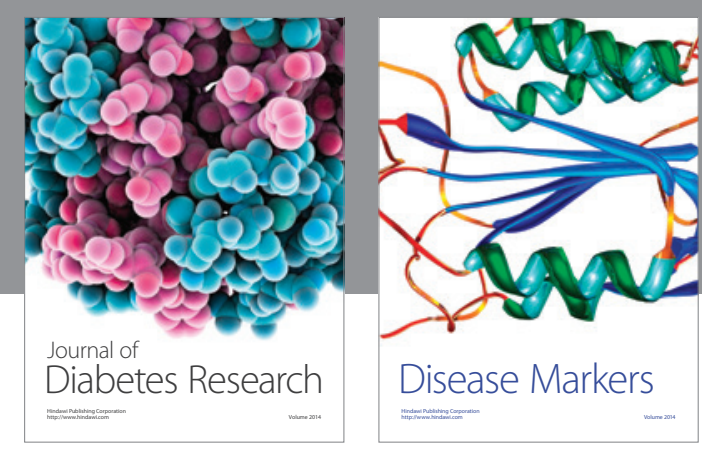

Disease Markers
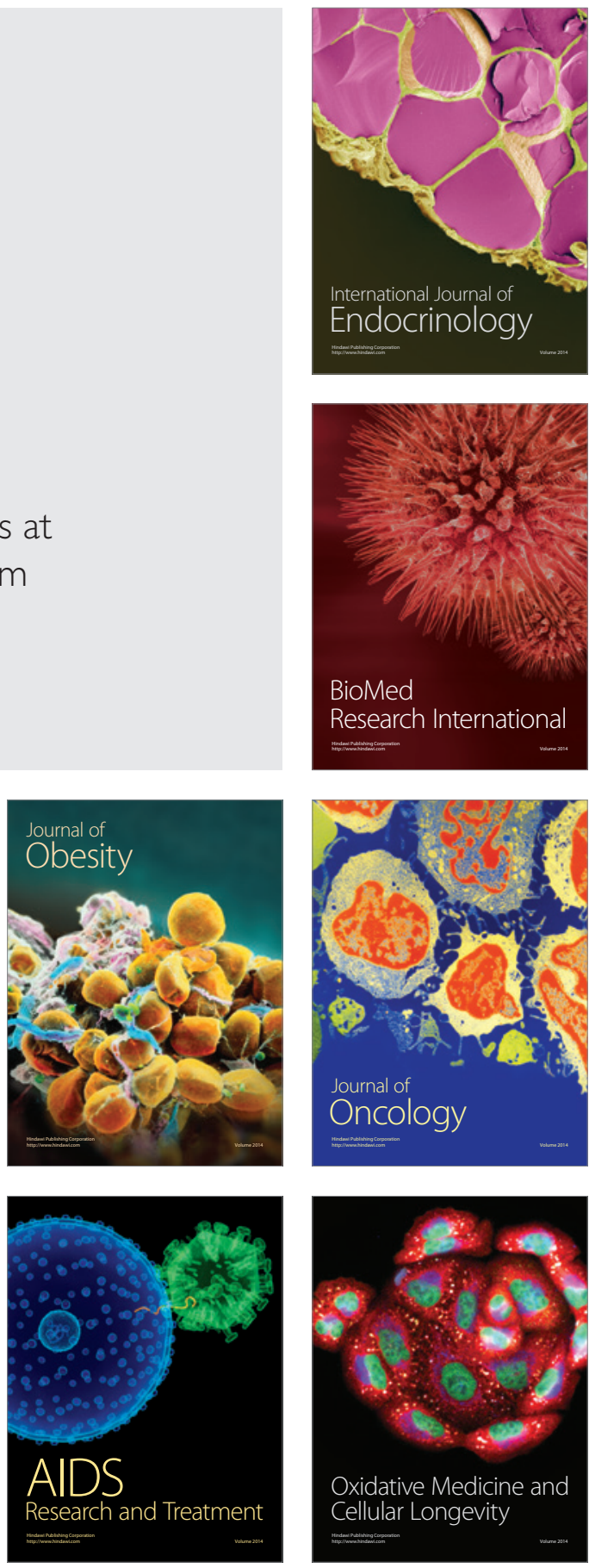